\title{
Sizing of a combined series-parallel hybrid architecture for river ship application using genetic algorithm and optimal energy management
}

\author{
Romain Derollepot \\ and Emmanuel Vinot \\ IFSTTAR \\ 25 Av. Francois Mitterrand \\ 69675 Bron - France
}

\begin{abstract}
A good way to reduce the fuel consumption of a commercial river ship can be the hybridization of the system. Sizing the system related to its actual use and energy management is then a key-point. In this paper a global sizing method based on Genetic Algorithm and dynamic programming is proposed. It allows the sizing of a complex series-parallel architecture on uses cycles which are developed using measurements on real ship. The study shows potential reduction of fuel consumption around $10 \%$, and proposes some leads to reduce the pollutant emissions.
\end{abstract}

Keywords: Hybrid architecture, Optimal control, Sizing process, River ship

\section{Introduction}

In a context of reduction of carbon dioxide emissions, Inland Waterways Transport (IWT) may be a good alternative to road transportation. Commercial river ships that can carry from 2000 to 5000 tons still present a better ratio of fuel consumption per tons carried than trucks [1],[2]. However, few effort has been made trying to reduce the fuel consumption of ships compared to road transportation.

A solution to reduce the fuel consumption of ships is to replace the existing powertrain by a hybrid architecture. Electrical mode and engine downsizing can then be used in an efficient manner to reduce fuel consumption and pollutant emissions. Many authors focus on serial-architecture [3] for 
submarine [4], small passenger ship [5], or boat used in protected marine area [6]. However this architecture should be not optimal due to cascading efficiency in electrical machines and converters. More complex architecture should then be more efficient as described in [7] for a hybrid tug.

This paper focuses on a commercial river ship of pusher type fig.1. This ship is designed to push barges tied to its front. On the figure the pusher is only the small ship at the end of the convoy and is mainly composed of an engine room and a wheelhouse. With such a type of ship, only the barges are docked during loaded phases when the ship pushes other barges. Thus the ship is often in use when the barges are tied and untied. The fuel consumption of such ships can then reach 400000 liters of fuel per year.

Three hybrid architectures have been sized and compared in this study. The key-points are then the sizing and the management of the system to ensure the best fuel economy. This paper focuses on these two points in order to find the best sizing and energy management for a given use of the boat.

To solve the combined optimization problem of the sizing and the management of the system a global approach has been proven to be the most efficient for road hybrid vehicle with one engine [8],[9],[10]. The energy management can then be calculated in an optimal manner [11],[12],[13] or with methods close to optimality [14],[7].

In this paper an optimal energy management using the dynamic programming (DP) method has been developed [15], and is inserted in a main optimization loop managed by a genetic algorithm. The power-train architecture is much more complex than that of a road vehicle especially due to the number of engines. Thus the energy management is more complex to develop due to more possible operating modes and more degrees of freedom. The DP method has then been developed to a complex hybrid architecture with three engines which can be operated in four modes. It allows to evaluate the potential of fuel economy according to the size of the components and especially the size of the main engines and battery.

First, this paper presents the proposed hybrid architectures. Then, the sizing process and its application to a complex hybrid architecture are described in part 3. Section 4 and 5 present the modeling of the components of the powertrain, of the uses of the ships and the energy management method developed to assess the fuel consumption. Finally, the application of the developed sizing process and the obtained Pareto front are presented sec. 6 . 


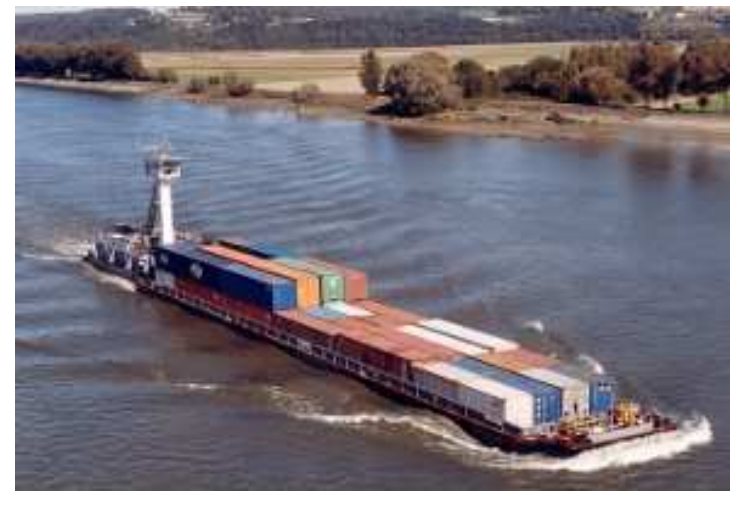

Figure 1: Pusher with barge

\section{Hybrid architectures}

As many commercial river ships, the powertrain of the pusher (fig. 2) possesses two independent propulsion lines. Each line is composed of an internal combustion engine (ICE) of high power, multi-disk clutch, final-gear and propeller. One or more electrical generator (ICE + electrical machine $(\mathrm{EM})$ ) provide the power to the servitudes of the ship (front propeller, onboard electricity, hydraulic-pressure, winch, wheelhouse...). 


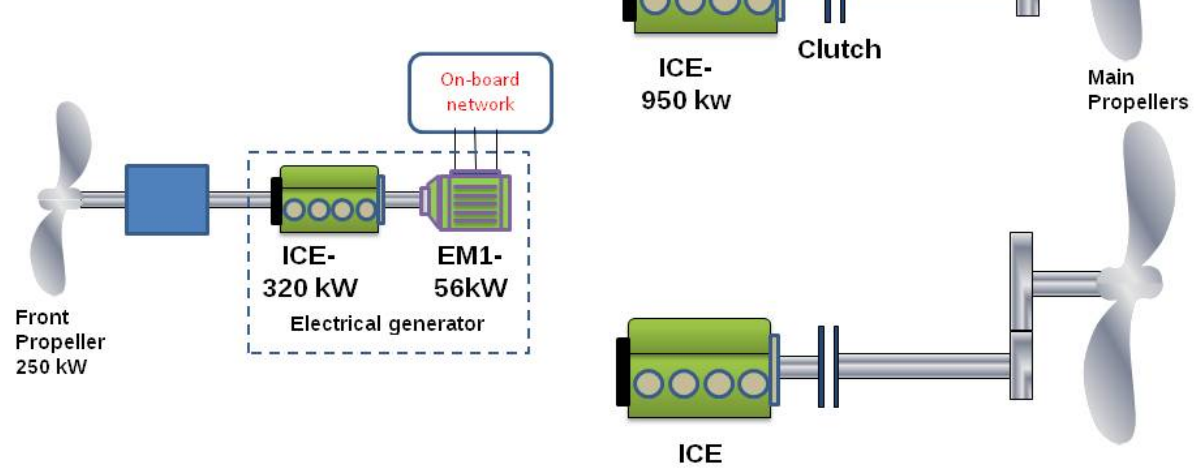

Figure 2: Conventional architecture

Different possibilities of hybridization can be studied and compared. In the scope of this paper, only the possibilities of series, parallel or "combined" series-parallel hybridization have been studied and compared to the conventional (fig.2) architecture. Power split architectures [16], [17], as those used in automobile, have been judged too complex for river ships due to the presence of a planetary gear and two electrical machines for one propulsion line.

Three architectures have been sized and compared:

- a parallel architecture (adding one electrical machine mechanically connected to each ICE shaft, fig.3),

- a series architecture with no direct mechanical link between engines and propellers (fig.4),

- a combined series-parallel architecture (fig.5). Electrical machines are mechanically connected to the ICE shaft directly or by mean of a coupling device. One electrical generator (ICE + electrical machine) is 
connected to the electric network. The power of the generator can be high enough to provide a part of the required power to the propulsion and can allow pure series operation. The operating point of the system is chosen to obtain the minimum fuel consumption along a uses cycle (part. 5). It is noted that more than one electrical generator can be used, thus allowing a downsizing of the engine.

In the conventional architecture used in river ship, one or more auxiliary engines are used to provide the on-board electricity (fig.2) and the power to the front propeller (by mechanic or hydraulic coupling). In the proposed hybrid architectures, the electrical generator is removed and the front propeller is connected to an electrical machine linked to the on-board electric network. The next section proposes a sizing process of this complex hybrid architecture combining optimal control management and genetic algorithm.

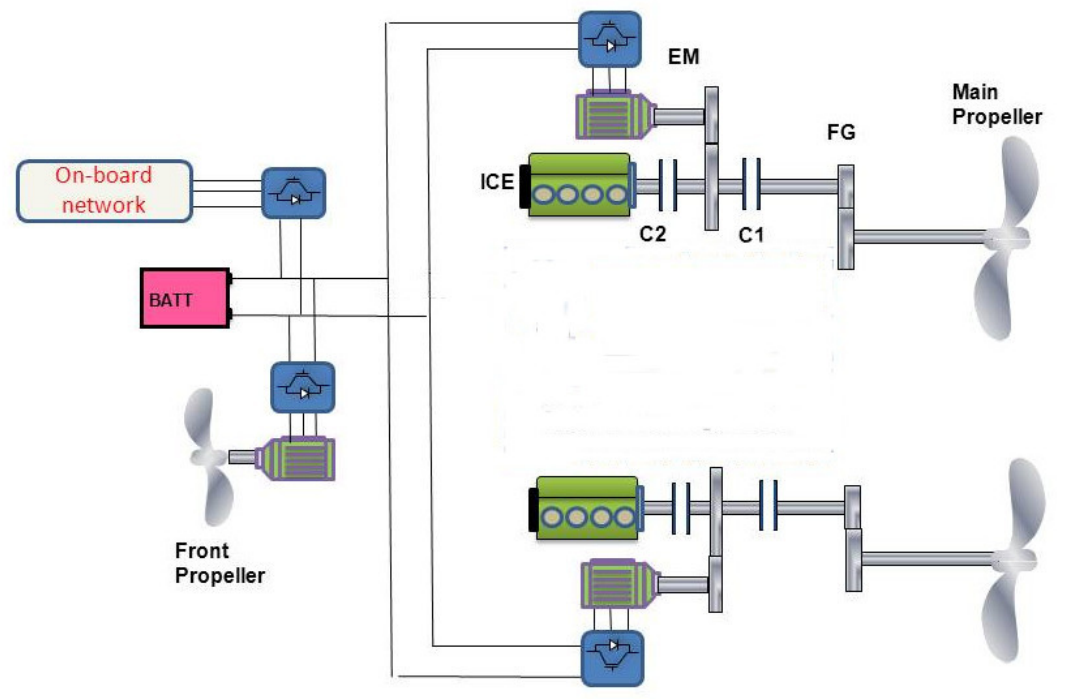

Figure 3: Parallel architecture. 


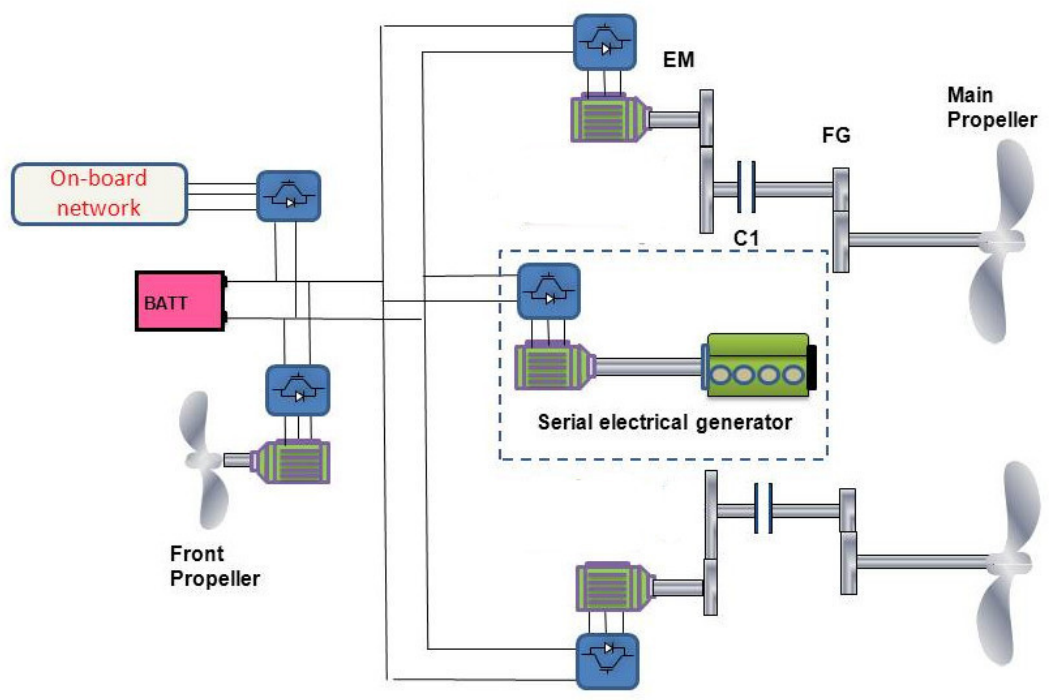

Figure 4: Serial architecture.

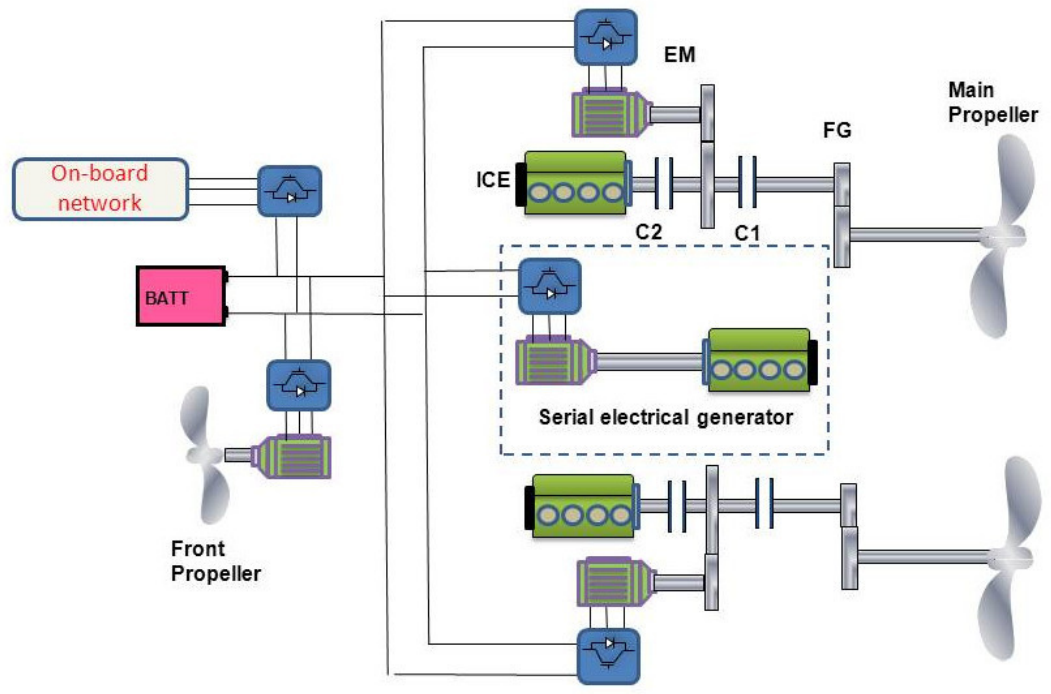

Figure 5: Combined series-parallel architecture. 


\section{Sizing process}

The sizing of a hybrid architecture is highly dependent on the management of the system. To give a suitable answer to this issue, the energy management can be determined using an optimal control method inserted in a main optimization process (fig.6). Coupling dynamic programming [15],[18] for the energy management and Meta-heuristic algorithm has been proven an efficient solution to size hybrid architectures dedicated to road transportation [19],[12],[10]. This process is applied in this study for the sizing of more complex architectures dedicated to river ship (fig.6). A Genetic Algorithm $[20]$ is used to find the optimal components size that minimizes different objectives such as fuel consumption and size or cost of the components (Main optimization process, fig.6). The fuel consumption is calculated by means of the dynamic programming (DP) method. For each sizing DP finds the optimal energy management of the system on a uses cycles (lower level control optimization, fig.6). For one operating point of the propeller, the system can be operated in different manners (electric, series, combined mode) leading to a sub-level of optimization included in the DP process (system operation optimization, fig.6). 


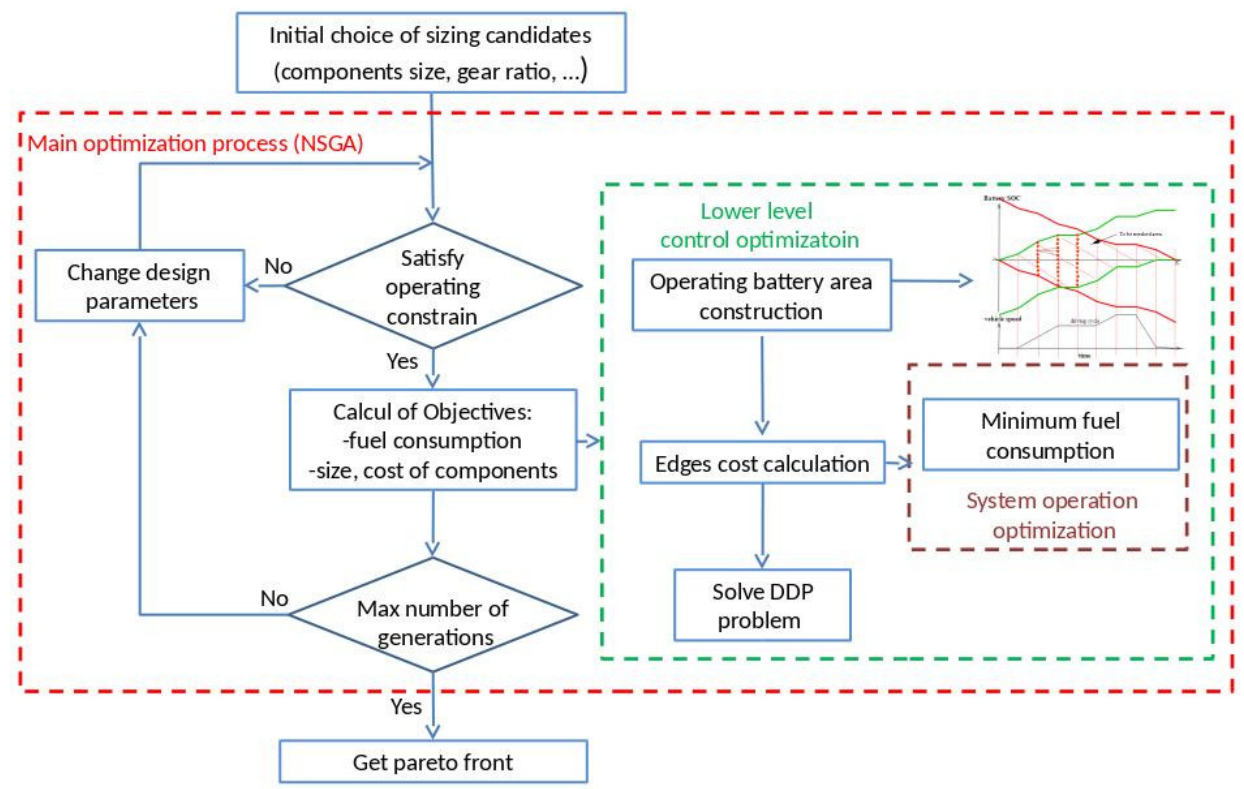

Figure 6: Sizing process

In the design and sizing process of hybrid architectures [21], [22], we commonly need models of the components and uses cycles in order to simulate the powertrain operations and to calculate the fuel consumption which is one of the objectives to be reduced. Next part focuses on those two points.

\section{Modeling of uses and components}

To simulate the fuel consumption of hybrid architectures, models of the architectures and thus of the components must be developed and validated (sec. 4.2). In addition, uses cycles have to be developed to represent the operations of the boat (main propeller speed, front propeller power and onboard servitude power).

\subsection{Uses cycles}

In order to simulate the operations of the ship in a representative manner, uses cycles describing the main propeller speed, the front propeller electrical power and the electrical power consumption of the servitudes have been generated using measurements. The ship has been monitored in a period of 
6 months, then the data have been compacted in a representative cycle of 2 hours which can be used to simulate the operations of the ship.

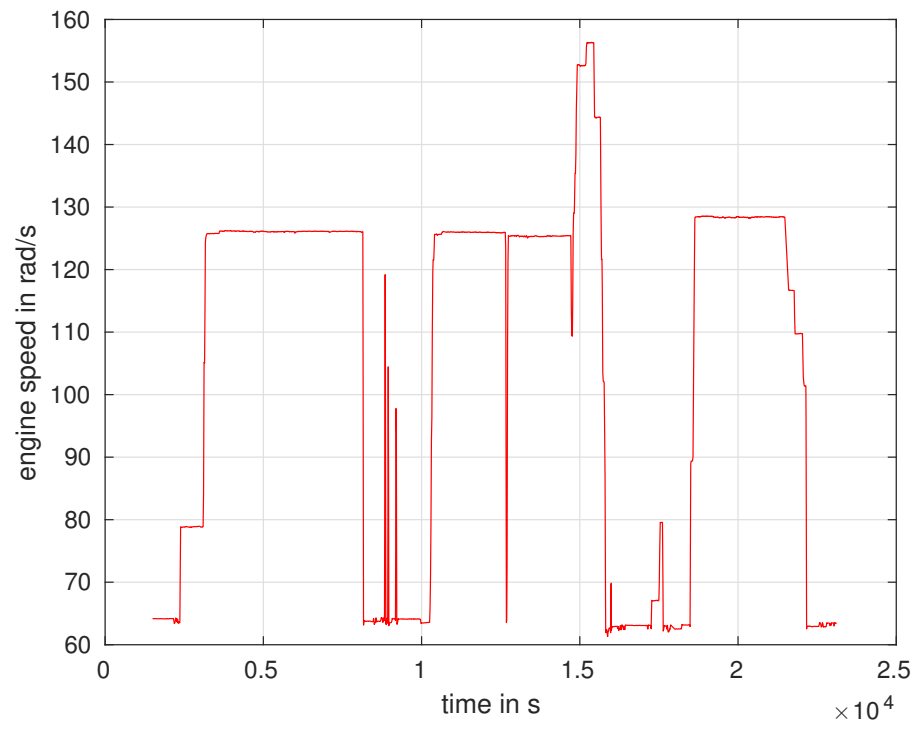

Figure 7: Main propeller speed: extraction on a small period of the six month of measurement

To generate this cycle, the main propeller speed measurements (fig. 7) have been sorted in classes of speed. Then the time passed in each class during the six months of measurement has been determined. The cycle has been generated with constant speed phases with a duration proportional to those measured. Figure 7 shows the engine speed on a period of 7 hours extracted from the 6 months measurements. The time between two phases where the engine is at idle speed $(63 \mathrm{rd} / \mathrm{s})$ corresponds to the time between two locks ${ }^{1}$. The mean period between two locks is around 2 hours on the trip. In fact, on the monitoring journey, the boat stop only when it reaches locks and final destination. A maneuver phase is then obserced (engine speed around $80 \mathrm{rd} / \mathrm{s}$ ) as wall as a stop of the boat on the lock where the main engine is at idle speed $(63 \mathrm{rd} / \mathrm{s})$. This duration of two hours has thus been chosen to generate a representative cycle (fig. 8). The other speeds of the engine $(128 \mathrm{rd} / \mathrm{s}$ and $158 \mathrm{rd} / \mathrm{s})$ correspond to cruising phases. The higher

\footnotetext{
${ }^{1}$ locks : gate on the river or canal to go up or down
} 
engine speeds are linked to a narrow pass on the river where the flow is high, a high propulsion power $(1900 \mathrm{~kW})$ is then required to cross this pass in complete security.

The same approach has been applied for the front propeller, taking into account that it is only used in phases of maneuver where the main propeller is shut off (engine on idle).

Finally, the electrical consumption power has also been sorted. The maximum observed in the power of the servitudes corresponds to the activation of the wheelhouse, which goes down before the passage of bridges and then goes up again. The mean duration between two peaks has been determined to be around 12 minutes which is the periodicity retained for the on onboard electrical consumption.

It has been verified that these cycles are energetically representative of the operations of the conventional ships. Table 1 present the fuel consumption of the engines, the mean on-board electrical consumption and the mean front propeller power calculated using the 6 months of measurement. The simulation results have been obtained with the model of the conventional ships using the components model described in section 4.2. The comparison between measurement and simulation shows less than $2 \%$ of differences. 

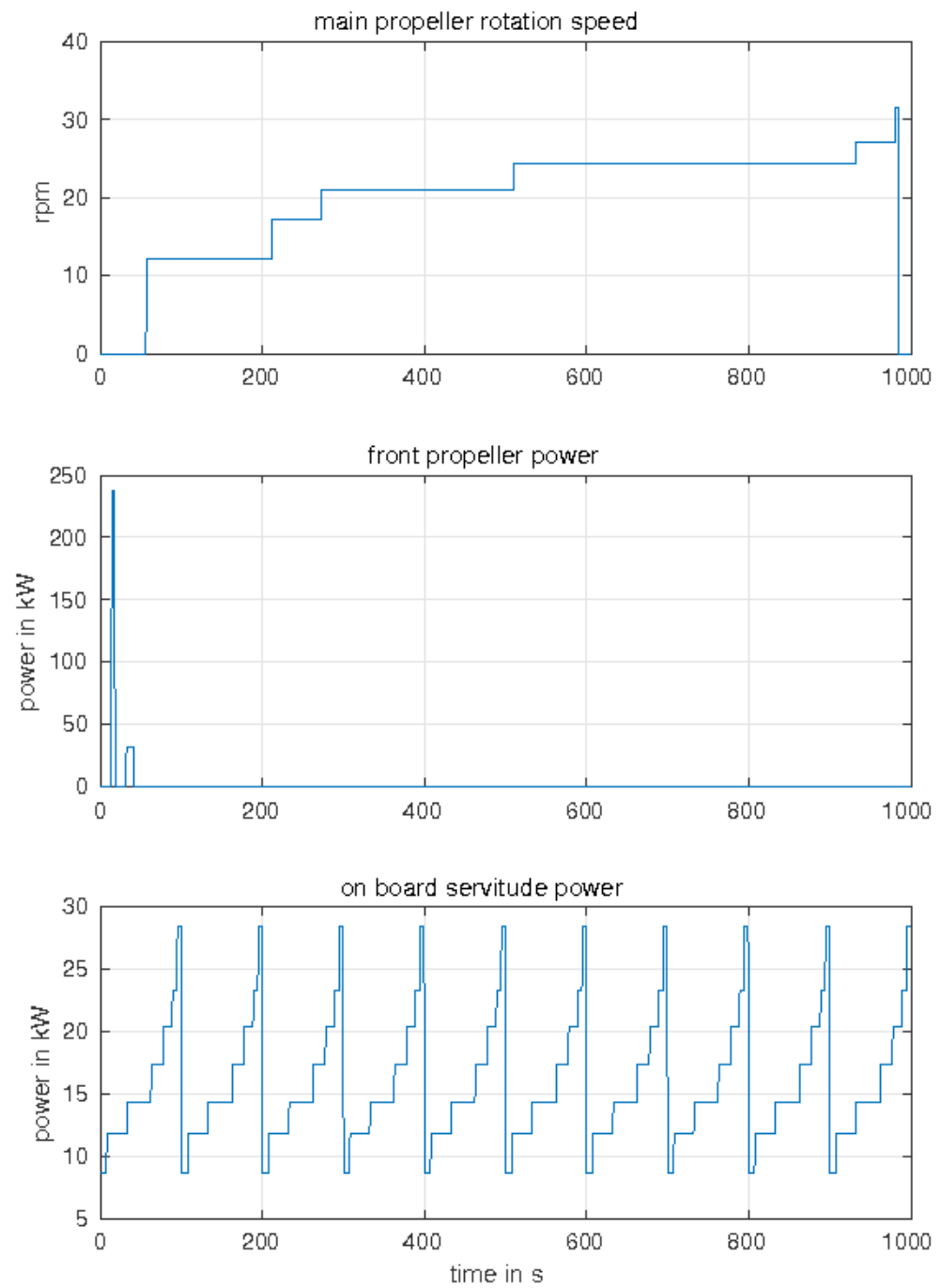

Figure 8: Uses cycle

It is noted that the speed evolution is only increasing in the generated cycle. In fact the sequences of speed do not influence the fuel consumption in our case. Using the DP the model of the battery is independent of SoC. Moreover, the dynamic of the shaft of the propeller is neglected. 
Table 1: Fuel consumption and electrical power

\begin{tabular}{ccc}
\hline & measurement & simulation on uses cycles \\
\hline Fuel consumption $\mathbf{l} / \mathbf{h}$ & 142 & 144.8 \\
\hline Mean electrical power & 15.4 & 15.6 \\
\hline Mean front propeller power & 1.2 & 1.2 \\
\hline
\end{tabular}

\subsection{Components model}

An important step to model existing conventional architectures and then hybrid architectures is to model the components of the power train.

The torque demand on the propeller can be modeled in different manners. A model of the hull of the ship can be performed and used to provide the drag force as it is usually done in modeling ground vehicles. Nevertheless, such an approach is difficult to perform in our case as the real speed of the ship on the water flow is difficult to evaluate. Moreover, the drag force in confined environment, such as rivers, is strongly dependent on the width and depth of the river (also difficult to measure). A choice has thus been made to model the drag force regarding only the propeller torque versus propeller speed characteristic.

The torque versus speed characteristics of the propellers has been deduced from steady state measurements. Fig.9 presents the measurement (torque and speed) performed on the left and right propeller for chosen points in steady state operations. The red points correspond to the right propeller and the blue points to the left propeller.

The propeller is an object in motion in the water. It is therefore only subject to fluid resistance. Thus it has been verified that its drag torque is a square function of the rotation speed eq. 1 .

$$
\Gamma=\alpha \times \Omega^{2}+\beta
$$




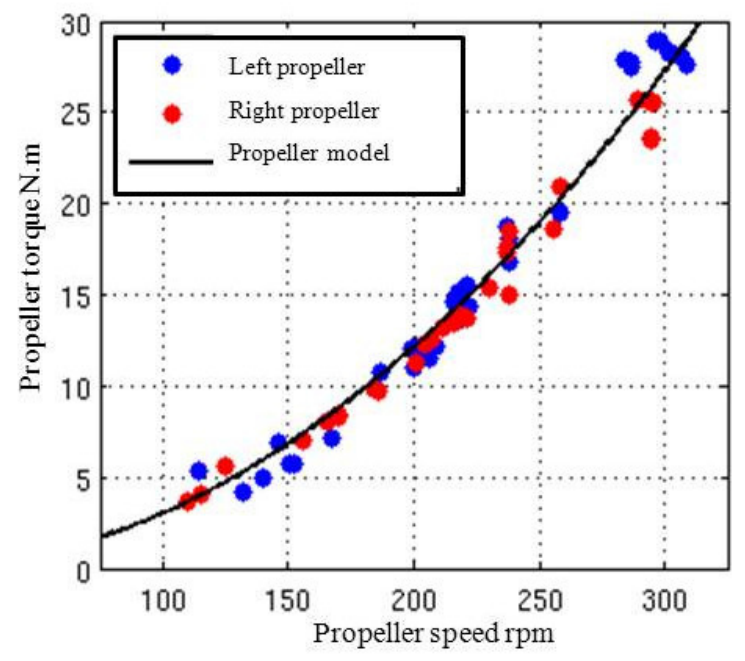

Figure 9: Propeller model

Going upstream to the others components, the final gear is represented with a gear ratio and a constant efficiency. The engines are modeled by classical fuel consumption maps which have been deduced using measurements on steady-state operations. The electrical machine and the inverter are represented with efficiency maps. The battery pack is modeled by classical serial resistive scheme (open circuit voltage in series with a resistance depending on the direction of the current (charge or discharge). The battery is composed of Lithium-Phosphate cells (9.12 Ah, $30 \mathrm{Wh}$ ) arranged in series and parallel.

Considering the model of each components, the VEHLIB library [16] is used to simulate the global system and solve the DP problem. The components are connected in a backward manner going upstream from propellers to engines and fuel consumption. For each time of the cycle previously described the fuel consumption can then be calculated for each possible mode in order to choose the more efficient (sec. 5). 


\section{Energy management}

\subsection{Dynamic Programming applied to combined series-parallel hybrid archi- tecture}

The fuel consumption of a hybrid system is strongly dependent on the energy management of the system. In a sizing process it is often solved in an optimal manner [23], [24]. The problem is then to find the optimal control of the system in order to minimize the fuel consumption (eq.2) along a known in advance driving cycle under a constraint of battery state of charge (SoC) (eq.3):

$$
\begin{gathered}
\left.J=\int_{t_{0}}^{t_{f}} \dot{m}_{f}(t)\right) d t \\
\Delta_{S O C}=\int_{t_{0}}^{t_{f}} \delta_{S O C}(t) d t=K
\end{gathered}
$$

In the case of the proposed series-parallel architecture (fig. 5), for a given speed of the main propeller several operating modes of the system are possible:

- pure electrical mode (C1 closed and C2 open, main engine and EG engine switched off),

- pure parallel hybrid mode (C1 and C2 closed, Engine of EG switched off),

- pure series hybrid mode (C1 closed and C2 open main engine switched off),

- combined hybrid mode (C1 and C2 closed and engine of EG on).

Moreover, when the EG is in operation, for a given electrical power $P_{E G}$ a choice of the speed (torque) of the engine of the EG can be performed to minimize the fuel consumption.

Dynamic programming (DP), [15] is a well known method to solve in an optimal manner the problem of energy management in hybrid vehicles. It has been proven an efficient method to solve optimal control for vehicles with 
one storage source [18],[25] as a battery. The SoC is considered as the state variable and depends only on the battery current.

The DP problem can be represented in a SoC sample area (fig. 10) where the states of a column are linked to the states of the following column by a spread of edges. Each edge corresponds to a battery current (SoC variation), and is associated with a fuel consumption. The maximum battery current -maximum discharge- is that of the pure electrical mode. The SoC can be sampled in order to ensure that, at each step of time, the pure electric mode (which is the maximum battery current) corresponds to one edge of the graph (fig. 10), [18]. In this case $P_{E G}$ is equal to zero. Using the Bellman principle [15] the optimal battery current is then determined and thus the electrical/hybrid mode choice is performed.

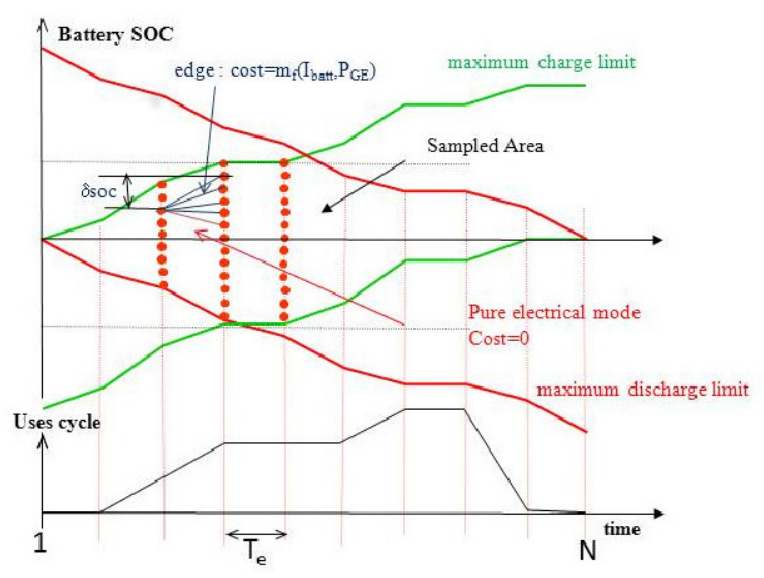

Figure 10: Dynamic programming optimal trajectory and limits

The other states are by definition hybrid modes. The choice between the different hybrid modes is performed by minimizing the fuel consumption versus EG power for a known battery current i.e. on each edge of the graph.

Looking at the equations of the system eq. 4 to eq.9 we obtain 6 equations and 7 unknown variables $\left(\Omega_{i c e}, \Omega_{e m}, T_{i c e}, T_{e m}, P_{e m}, P_{b a t t}, P_{E G}\right)$. It is then clear that choosing $P_{E G}$ for example will fix the operation of the system. For that $P_{E G}$ is sampled from 0 to the power of the electric generator in serial mode $\left(P_{E G-H S}\right)$ in each edge. The value corresponding to the minimum of fuel consumption is chosen. A value of zero corresponds to the pure parallel hybrid mode. $P_{E G-H S}$ is the maximum possible value of $P_{E G}$. It corresponds 
to the electrical power which has to be provided by the electrical generator if the main engines are switched-off (pure series mode) or to the maximum value of EG power. Intermediate values correspond to a combined series-parallel mode.

The optimization of the operations of the Electrical Generator -choice of torque and speed for a given electrical power- is performed once for all, generating an optimal power curve based on the characteristics of the engine and the electrical machine.

$$
\begin{aligned}
& \Omega_{\text {ice }}=\Omega_{\text {prop }} k_{f g} \\
& \Omega_{\text {em }}=\Omega_{\text {prop }} k_{c p l} k_{f g} \\
& \left(T_{i c e}+T_{e m} k_{c p l} \eta_{c p l}\right) \eta_{f g} k_{f g}=T_{p r o p} \\
& P_{e m}=T_{e m} \Omega_{e m}+P t_{e m}\left(T_{e m}, \Omega_{e m}\right) \\
& P_{\text {batt }}+P_{E G}=P_{\text {aux }}+P_{\text {frontprop }}+2 \cdot P_{\text {em }} \\
& P_{b a t t}=I_{b a t t} \cdot E_{b a t t}-R_{b a t t} \cdot I_{b a t t}^{2}
\end{aligned}
$$

\subsection{Results on Management}

Fig. 11 presents the operations of the system along a uses cycle. The following representative variables are presented:

- mechanical power of one of the main propellers,

- electrical power of the on-board servitudes and of the front propeller,

- SoC of the battery,

- electrical power of the battery and of the electrical generator and mechanical power of one of the main engines. 
Table 2: Symbols defintion

\begin{tabular}{ll}
\hline Symbol & Quantity \\
\hline$\Omega_{\text {ice }}$ & Main engines speed \\
\hline$T_{i c e}$ & Main engines torque \\
\hline$\Omega_{e m}$ & Electrical Machines speed \\
\hline$T_{e m}$ & Electrical Machines torque \\
\hline$P_{e m}$ & $\begin{array}{l}\text { Electrical Machines electrical } \\
\text { power }\end{array}$ \\
\hline$P t_{\text {em }}$ & Electrical Machines losses \\
\hline$P_{E G}$ & $\begin{array}{l}\text { Electrical generator electrical } \\
\text { power }\end{array}$ \\
\hline$P_{a u x}$ & Onboard Servitude electrical \\
& power \\
\hline$P_{f r o n t p r o p}$ & $\begin{array}{l}\text { Front } \\
\text { power }\end{array}$ \\
\hline$P_{b a t t}$ & Battery electrical power \\
\hline$E_{b a t t}$ & Battery open circuit voltage \\
\hline$I_{b a t t}$ & Battery current \\
\hline$R_{b a t t}$ & Battery internal resistance \\
\hline$\eta_{c p l}$ & coupling device on electrical \\
& machine efficiency \\
\hline$k_{\text {cpl }}$ & coupling device on electrical \\
& machine ratio \\
\hline$\eta_{f g}$ & final gear efficiency \\
\hline$k_{f g}$ & final gear ratio \\
\hline
\end{tabular}

The DP is applied for a sizing with three engines (two main engines and one engine for the electrical generator) of $375 \mathrm{~kW}$ and a battery of 300 kWh, (sec. 6). In this study only operations in charge sustaining mode are considered. No external battery recharge is taken into account and the final battery $\mathrm{SoC}$ is thus equal to the initial one $(\mathrm{K}=0$, eq.3).

It is noted that the SoC variation on the representative cycle is only on a window of $+10 \%,-18 \%$. The battery can be smaller with no significant effect on the fuel consumption. In fact its size is imposed by a constraint on battery energies to respect a minimum on-board available power (sec.3).

The parameters of the DP process are presented in Table 3 . It takes 
around 52s on an Intel Xeon E5-2637 @ $3.5 \mathrm{gHz}$ to solve the DP problem with a time sample of $1 \mathrm{~s}$. Around $60 \%$ of the time is dedicated to the calculus of the costs of the edges (choice of optimal operations of the system for a given battery current).

Table 3: graph parameter

\begin{tabular}{ll}
\hline step of time & $1 \mathrm{~s}$ \\
\hline SoC Sample & $0.02 \%$ \\
\hline number of edges & $5 \cdot 10^{8}$ \\
\hline
\end{tabular}

In fig. 11, looking at the power of the battery, of the main engine and of the EG, the different operations of the system can be observed:

- pure electrical mode from $t=400$ s to 1500 s for example. It corresponds to maneuver phases with low required power on the main propeller or on the front propeller, the battery provides all the energy required by the main propeller and the on board servitude,

- from 100 s to 123 s the front propeller is driven by the electrical generator in a serial manner. The power of the front propeller is too high to operate the system in pure electrical mode in an efficient manner considering charge sustaining,

- parallel hybrid mode can be observed from 1500s to 1950s for example. It corresponds to low speed propulsion phases. The battery is charging during these phases, the engines provide the power required for the propulsion, the auxiliary and to recharge the battery,

- pure mechanical phases can be observed (from 2150s to $2800 \mathrm{~s}$ ) when the energy is quite only provided by the main engine with direct mechanical connection to the propeller,

- finally the system is operated in a combined series-parallel mode from 3665s to the end of the cycle, which corresponds to high speed propulsion phases. The power of the main engines is lower than the power required by the propellers. In these phases the engines are at their full-power. When the required power is not too high the battery is recharged and the stored energy will be used to provide the required power at the end of the cycle, 
- to reach the final required SOC, the combined hybrid mode is also used to recharge the battery for example from instant 2790 to 2870 when it alternates with pure parallel hybrid mode. The EG is then on when the on-board servitude power is high.
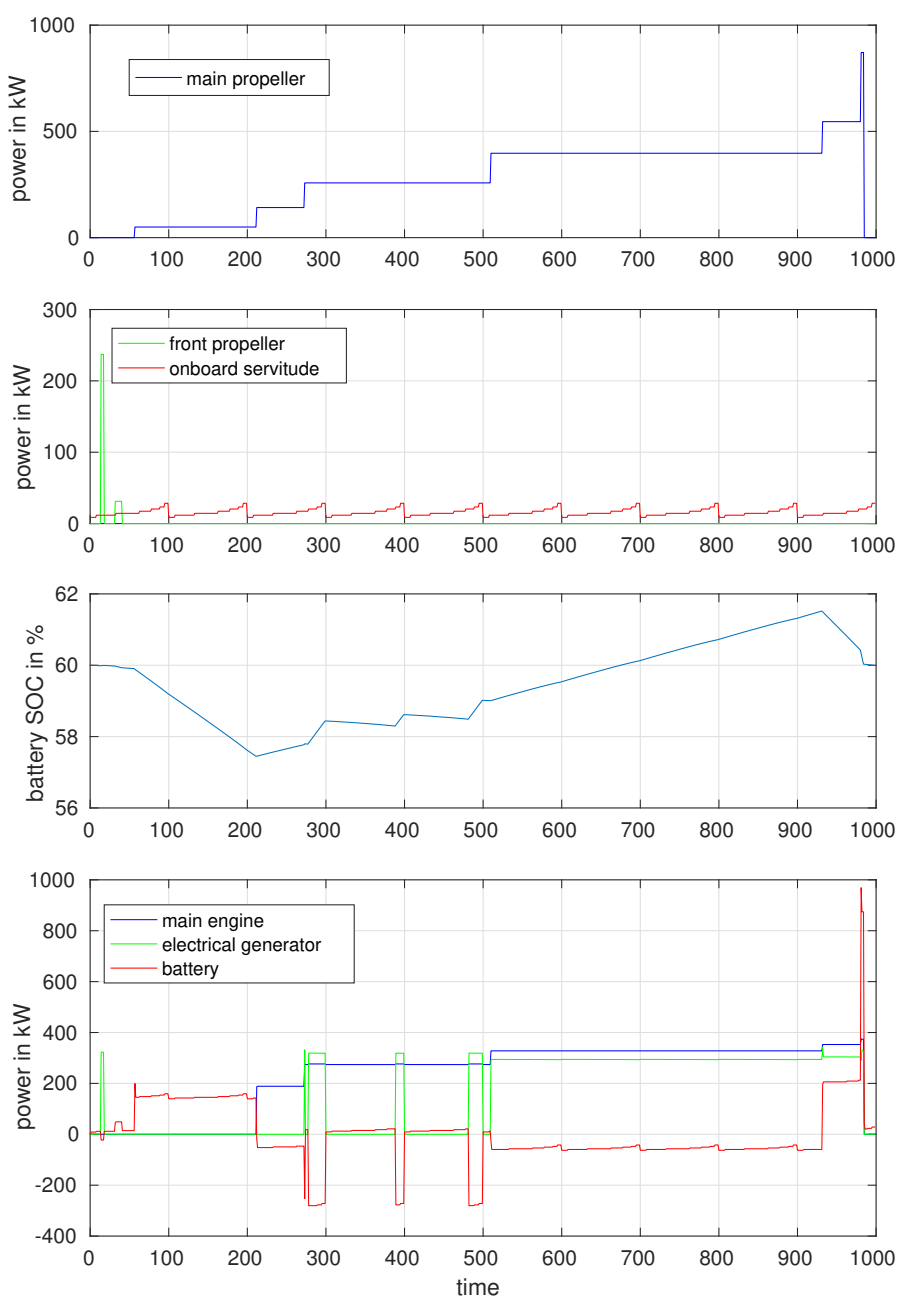

Figure 11: Energy Management Strategy 


\section{Results and discussion}

This part present the sizing of a combined series-parallel architecture for a river-ship of pusher type. The previously proposed method has been applied. Multi-objective algorithm (NSGA-II, [20]) is used to solve the sizing problem with an embedded optimal energy management previously presented, to asses the fuel consumption.

The following three objectives to minimize are chosen:

- the fuel consumption calculated using optimal energy management (sec. 5).

- the power of the main engine which is representative of its cost and can be an important parameter of choice (see discussion),

- the battery energy storage capacity which is also representative of its cost and size,

The power of the electrical machine in parallel (EM) and of the electrical generator (engine plus electrical machine) can also be some objectives to minimize but are in fact fixed by the constraint of the systems (see the following).

It is quite impossible to evaluate the cost of the overall architecture. In fact it strongly depends on components which are not developed in high series. The cost of the main engines is thus not linked to its power. And the cost to prototype the electrical part is quite impossible to asses. Thus, to answer this issue we chose the previous three objectives. After the sizing process, the power of each components is known, a choice can then be performed integrating different considerations like cost, or volume of the systems.

Four variables of optimization are used in the NSGA process:

- the main engine power $\left(P_{I C E}\right)$,

- the power the electrical machines in parallel $\left(P_{E M}\right)$,

- the power of the electrical generator $\left(P_{E G}\right)$,

- the battery energy storage capacity $\left(E_{B A T T}\right)$. This will vary considering the number of cells of the battery pack. 
The following constraints are applied to the systems:

- the global propulsion power needs to be superior or equal to those of the original architecture, i.e. $950 \mathrm{~kW}$ for each shaft:

$$
P_{\text {em }}+P_{\text {ice }}>=950 k W
$$

- the maximum power of the conventional architecture $(1900 \mathrm{~kW})$ has to be available for 10 minutes. As the global power provided by the engines is lower than $2 * 950 \mathrm{~kW}$, this will fix the battery energy taking into account that the battery will be discharged by only $50 \%$ in 10 minutes.

$$
\begin{gathered}
E_{\text {sbatt }}>=\left(\frac{1900-2 \cdot P_{\text {ice }}}{\eta_{\text {em }}}-P_{E G}\right) \cdot T_{d} \cdot \frac{100}{\Delta S o C} \\
E_{\text {sbatt }}>=\frac{1}{3}\left(\frac{1900-2 \cdot P_{\text {ice }}}{\eta_{\text {em }}}-P_{E G}\right)
\end{gathered}
$$

Where $E_{\text {sbatt }}$ is the energy stored in the battery fully charged (expressed, in Wh), $\eta_{e m}$ is the mean efficiency of the electrical machine and converter, $T_{d}$ is the time of discharge (1/6 hours in ours case) and $\triangle S o C$ is the discharge of the battery during $T_{d}(50 \%)$.

Table 4 presents the main parameters used to run the NSGA algorithm. The sizing process take around 3 days on an Intel Xeon E5-2637 @ $3.5 \mathrm{gHz}$. The NSGA optimization is parallelized on height core. The parameters used

\begin{tabular}{|c|c|}
\hline number of individuals & 60 \\
\hline number of generations & 500 \\
\hline crossover rate & 0.8 \\
\hline$P_{I C E} \min / \max$ & {$\left[\begin{array}{ll}50 & 950\end{array}\right] \mathrm{kW}$} \\
\hline$P_{E M} \min / \max$ & {$\left[\begin{array}{ll}50 & 950\end{array}\right] \mathrm{kW}$} \\
\hline$P_{E G} \min / \max$ & {$[50750] \mathrm{kW}$} \\
\hline$E_{B A T T} \min / \max$ & {$\left[\begin{array}{ll}30 & 600\end{array}\right] \mathrm{kW} . \mathrm{h}$} \\
\hline
\end{tabular}
for DP are those presented tab. 3 for DP.

Table 4: NSGA parameter 


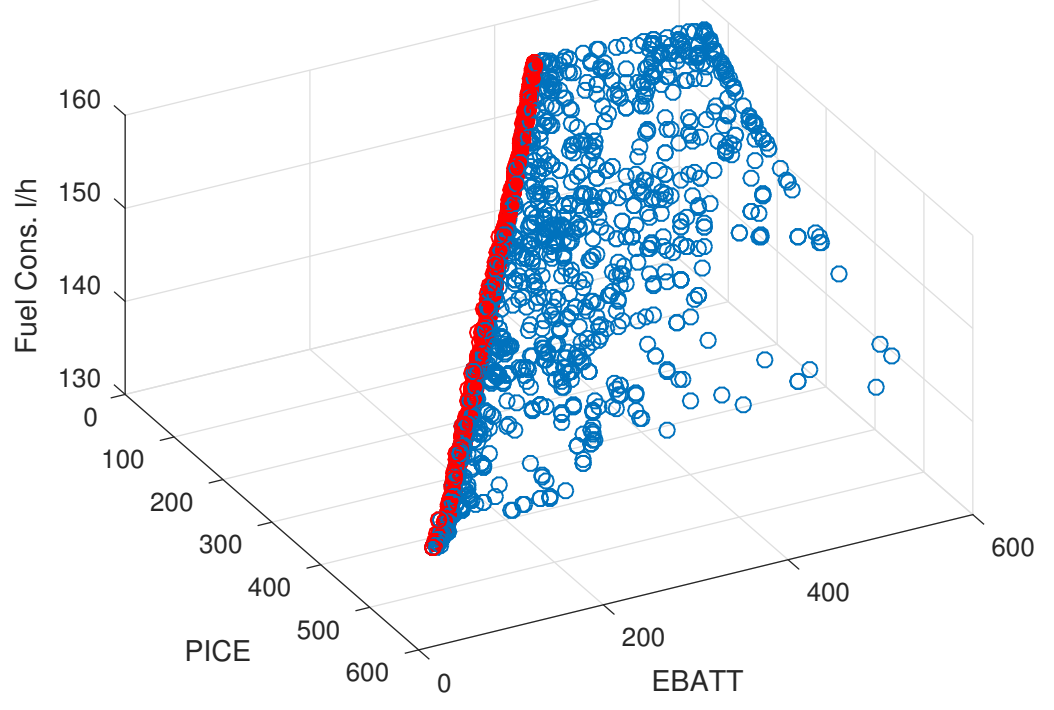

Figure 12: Pareto front 


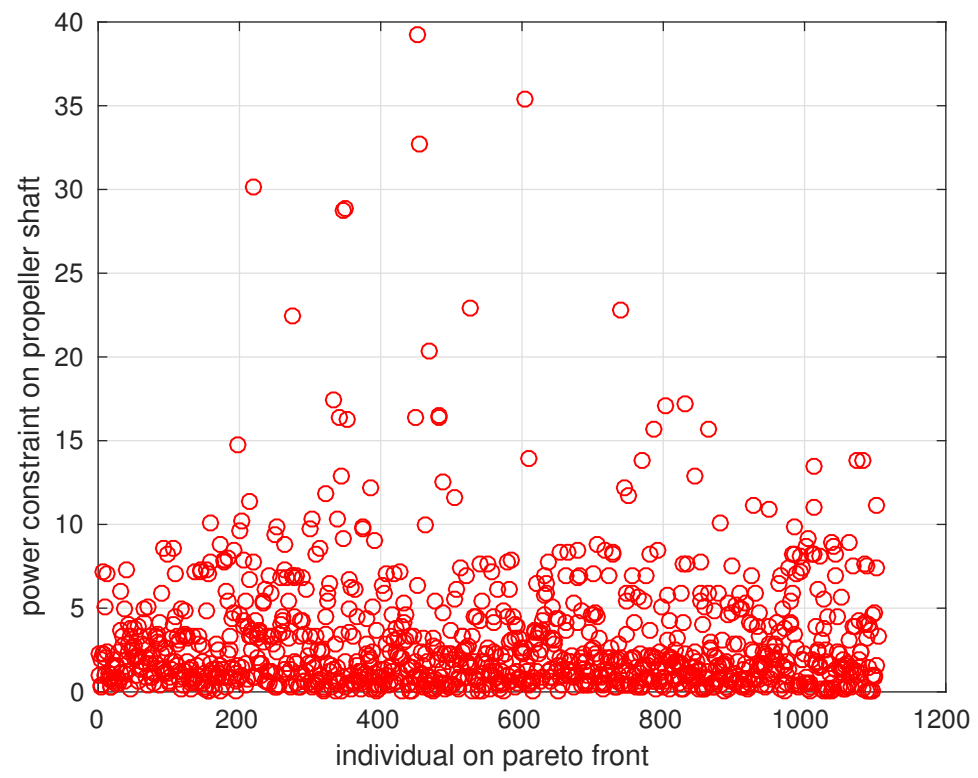

Figure 13: constraint on global power 
Figure 12 shows the Pareto front, fuel consumption versus engine power and battery energy storage capacity, obtained with the previously proposed sizing process for a series-parallel hybrid architecture (fig.5). The red point represent the constraint on the battery energy storage capacity $E_{B A T T}$ (eq. 10) for the maximum power of the EG $(750 \mathrm{~kW})$. The sizing with smaller engine and /or battery are not in the studied domain.

The two inequality constraints on the global propulsion power (eq. 10) and the battery energy storage (eq.12) behave in fact as equality constraint. The global energy power is quite equal to $950 \mathrm{~kW}$ and the battery energy storage capacity also corresponds to the minimum allowed by the constraint. Figure 13 represents the difference between the global power on each shaft minus $950 \mathrm{~kW}$, in percent of the minimum power allowed $(950 \mathrm{~kW})$ by the constraint:

$$
\frac{\left(P_{I C E}+P_{E M}\right)-950}{950} * 100
$$

It is clear that the great majority of the individuals respect the constraint with less than $5 \%$ of exceed. The same results are observed considering the battery energy storage capacity. This validates the choice not to consider EM and EG power as objectives.

The Pareto front is quite a plane. This means that for a given engine power the influence of the size of the battery does not act on the fuel consumption. In fact to respect the constraints, the EG size grows up when the battery size becomes smaller. But no significant difference can be observed in fuel consumption if energy is provided by battery or EG. 


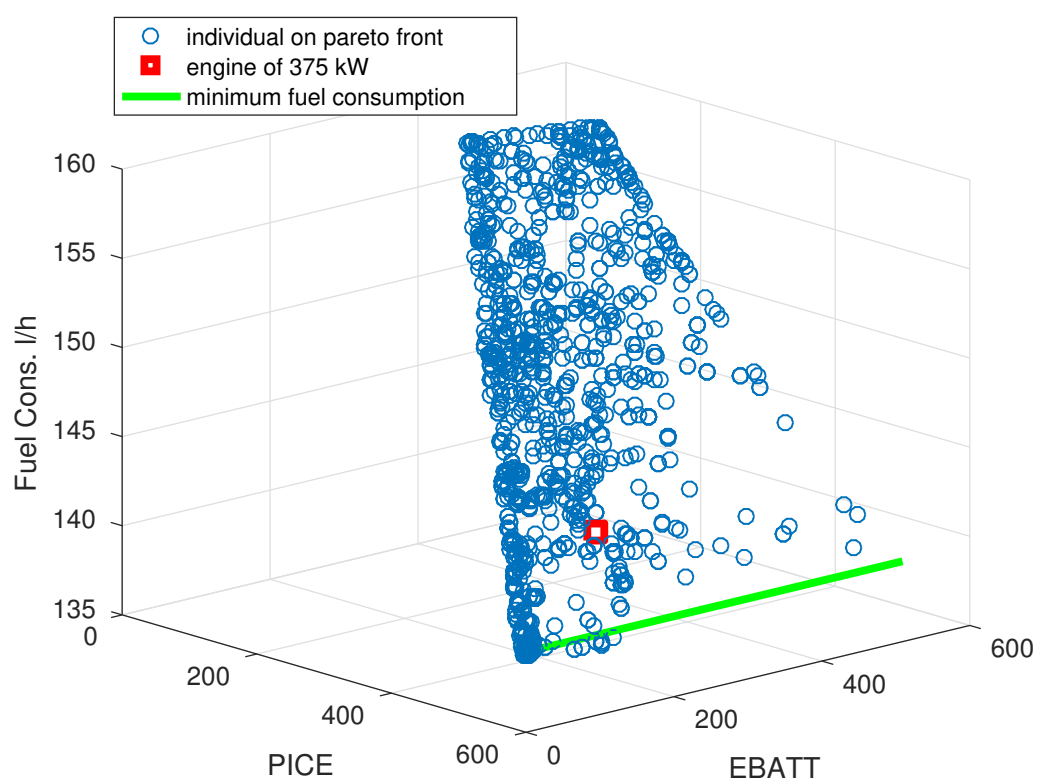

Figure 14: Pareto front

Some interesting sizings can be extracted from the Pareto front (fig. 14) as they present other interests than only a potential gain in fuel consumption. Table 5 presents this sizing with the corresponding power of the main engine (ICE) of the parallel Electrical Machine (EM), of the electrical generator (EM) and of the weight of the battery (BATT) considering a mass energy of $100 \mathrm{Wh} / \mathrm{kg}$.

The minimum of fuel consumption (architecture III, tab.5) is expected with an engine of $500 \mathrm{~kW}$ (green line on fig.14). A gain of $12 \%$ is then obtained compared to the conventional architecture. Different couples EG/battery can match the constraint (eq. 10 and eq.12), from pure parallel architecture to architectures with one or two electrical generators of $375 \mathrm{~kW}$. An architecture with one EG of $375 \mathrm{~kW}$ is presented in the table.

In this architecture, the main engines are downsized $(500 \mathrm{~kW}$ compared to $900 \mathrm{~kW}$ in the conventional powertrain) but not enough to use engines dedicated to trucks which have a maximum available power of around 375 $\mathrm{kW}$. River ships which are currently propelled by conventional powertrain are often not equipped with depollution devices (catalytic converter, partic- 
ulate filter ...). The pollution of the ships per tons $/ \mathrm{km}$ is thus at a level between euro II and euro $\mathrm{V}$ ground vehicle norms [1]. This will change in 2020 as the euro VI norm is planed to be applied to IWT. Adapting road engines dedicated to trucks can be a good solution to meet this issue and to reduce the global cost of hybridization while using already mass production engines. Architecture IV (tab.5) presents a solution using 3 engines of 375 $\mathrm{kW}$ dedicated to trucks (red point on fig.14 ). Two engines are on the main shaft and one is used for EG. The fuel consumption is then a bit higher than the minimum possible $(140.8 \mathrm{l} / \mathrm{h}$ versus $137.5 \mathrm{l} / \mathrm{h})$. However, $10 \%$ of fuel economy can be expected knowing that a pusher uses $400000 \mathrm{l}$ of fuel per year. The size of the battery (3 tonnes) remains reasonable (for a boat of 2000 tonnes). Moreover, compared to a pure parallel architecture, the presence of the electrical generator can provide driving comfort in maneuver phases if not possible using only the battery.

Two other sizings (II and V) have been treated separately from the sizing process. Solution II presents the case of a minimalist hybridization based on the existing architecture and adding two small EMs and a small battery. It shows a good potential of fuel economy $(7 \%)$ at small cost. Finally, solution $\mathrm{V}$ presents the case of pure series architecture. It shows that for such an application this solution is of no interest regarding fuel consumption. In fact, most of the energy is used for the main propellers. The decoupling between the propeller speed and the engine speed which allows to operate the engines in good specific consumption area cannot compensate the cascading efficiencies of the EM machines and converters.

Table 5: selected architectures 


\begin{tabular}{|c|c|c|c|c|c|c|c|}
\hline & \multirow{2}{*}{ architecture } & $\mathrm{ICE}$ & $\mathrm{EM}$ & $\mathrm{EG}$ & $\mathrm{BATT}$ & fuel & gain \\
\cline { 3 - 8 } & & $\mathrm{kW}$ & $\mathrm{kW}$ & $\mathrm{kW}$ & Tonnes & $\mathrm{l} / \mathrm{h}$ & $\%$ \\
\hline & & & & & & & \\
\hline I & Conventionnal & $2 \star 950$ & & & & 156,9 & 0 \\
\hline & & & & & & & \\
\hline II & Parallel & $2 \star 950$ & $2 \star 125$ & & 0,4 & 145,8 & 7 \\
\hline & & & & & & & \\
\hline III & Series-Parallel & $2 \star 500$ & $2 \star 450$ & $1 \star 375$ & 1,7 & 137,5 & 12 \\
\hline & & & & & & & \\
\hline IV & Series-Parallel & $2 \star 375$ & $2 \star 575$ & $1 * 375$ & 3 & 140,8 & 10 \\
\hline & & & & & & & \\
\hline $\mathrm{V}$ & Series & & $2 \star 950$ & $2 \star 500$ & 4,4 & 157 & 0 \\
\hline
\end{tabular}

\section{Conclusion}

This paper presents a study of the potential of combined series-parallel hybridization of river ships. An optimal sizing process embedding an optimal control has been developed and applied on a complex series-parallel architecture. A Pareto front representing fuel consumption versus the size of the components is then obtained and can be used to make a final choice of the architecture. Fuel economy between 12 and $7 \%$ can be performed depending on the size of the different components.

This study shows that the use of engines dedicated to trucks is possible. It can reduce the pollutant emission drastically using standard depollution devices. With three engines - two connected in parallel and one in series and 3 tons of battery, it is shown that a fuel economy of $10 \%$ can be expected. Taking into account that the fuel consumption of a ship of pusher type is around 400000 l/year, 40000 liters of fuel can be saved each year.

\section{Acknowledgements}

This work was performed during the Project PROMOVAN (http://www.promovan.tla.net/) regrouping French government agencies and industrial actors of the IWT domain. This Project was supported by European Regional Development Fund (ERDF) and the CPIER fund involving the French Rhône-Alpes Région. 


\section{References}

[1] D. Pillot, D. Guiot, B. Le Cottier, P. Perret, P. Tassel, Exhaust emissions from in-service inland waterways vessels, Journal of Earth Sciences and Geotechnical Engineering 4 (4) (2016) 205-225.

URL http://scienpress. com/download.asp?ID=1931

[2] S. Minami, T. Toki, N. Yoshikawa, T. Hanada, M. Ashida, S. Kitada, K. Tsukuda, A newly developed plug-in hybrid electric boat (pheb), Journal of Asian Electric Vehicles 8 (1) (2010) 1385-1392.

[3] K. Bellache, M. Camara, Z. Zhou, B. Dakyo, Energy management in hybrid electric boat based on frequency distribution approach-using diesel, lithium-battery and supercapacitors, in: Vehicle Power and Propulsion Conference (VPPC), 2015 IEEE, IEEE, 2015, pp. 1-6.

[4] B. A. Skinner, P. R. Palmer, G. T. Parks, Multi-objective design optimisation of submarine electric drive systems, in: Electric Ship Technologies Symposium, 2007. ESTS'07. IEEE, IEEE, 2007, pp. 65-71.

[5] W. lhomme, J. Trovao, Diesel-electric excursion ships enhancement using energetic macroscopic representation, in: Electrimacs 2017, 2017, pp. 1-6.

[6] G. Barabino, M. Carpaneto, L. Comacchio, M. Marchesoni, G. Novella, A new energy storage and conversion system for boat propulsion in protected marine areas, in: Clean Electrical Power, 2009 International Conference on, IEEE, 2009, pp. 363-369.

[7] T. Hofman, M. Naaborg, E. Sciberras, System-level design optimization of a hybrid tug, in: vppc 2017, 2017, pp. 1-6.

[8] E. Vinot, Comparison of different power-split architectures using a global optimisation design method, Int. J Electric and Hybrid Vehicles 8 (3) (2016) 225-241. doi:10.1504/IJEHV.2016.10000953.

[9] E. Silvas, T. Hofman, N. Murgovski, P. Etman, M. Steinbuch, Review of optimization strategies for system-level design in hybrid electric vehicles, IEEE Transactions on Vehicular Technology. 
[10] T. Nuesch, T. Ott, S. Ebbesen, L. Guzzella, Cost and fuel-optimal selection of hev topologies using particle swarm optimization and dynamic programming, in: American Control Conference (ACC), 2012, IEEE, 2012, pp. 1302-1307.

[11] V. Reinbold, E. Vinot, L. Garbuio, L. Gerbaud, Optimal sizing of an electrical machine using a magnetic circuit model: application to a hybrid electrical vehicle, IET Electrical Systems in Transportation 6 (1) (2016) 27-33. doi:10.1049/iet-est.2015.0008.

[12] C. Bertram, D. Buecherl, A. Thanheiser, H. Herzog, Multi-objective optimization of a parallel hybrid electric drive train, in: Vehicle Power and Propulsion Conference (VPPC), 2011 IEEE, IEEE, 2011, pp. 1-5.

[13] Z. Song, X. Zhang, J. Li, H. Hofmann, M. Ouyang, J. Du, Component sizing optimization of plug-in hybrid electric vehicles with the hybrid energy storage system, Energy 144 (2018) 393-403.

[14] J. Zhao, A. Sciarretta, A fully-analytical fuel consumption estimation for the optimal design of light-and heavy-duty series hybrid electric powertrains, Tech. rep., SAE Technical Paper (2017).

[15] R. Bellman, Dynamic Programming, Princeton University Press, 1957.

[16] E. Vinot, J. Scordia, R. Trigui, B. Jeanneret, F. Badin, Model simulation, validation and case study of the 2004 ths of toyota prius, International Journal of Vehicle Systems Modelling and Testing 3 (3) (2008) 139-167.

[17] M. Kamiya, Development of traction drive motors for the toyota hybrid system, IEEJ TRANSACTIONS ON INDUSTRY APPLICATIONS D 126 (4) (2006) 473.

[18] E. Vinot, Time reduction of the dynamic programming computation in the case of hybrid vehicle, in: Optimization \& Inverse Problems in Electromagnetism (OIPE), 2014.

[19] E. Silvas, E. Bergshoeff, T. Hofman, M. Steinbuch, Comparison of bilevel optimization frameworks for sizing and control of a hybrid electric vehicle, in: Vehicle Power and Propulsion Conference (VPPC), 2014 IEEE, 2014, pp. 1-6. doi:10.1109/VPPC.2014.7007029. 
[20] K. Deb, A. Pratap, S. Agarwal, T. Meyarivan, A fast and elitist multiobjective genetic algorithm: Nsga-ii, IEEE transactions on evolutionary computation 6 (2) (2002) 182-197.

[21] B. Huang, Z. Wang, Y. Xu, Multi-objective genetic algorithm for hybrid electric vehicle parameter optimization, in: Intelligent Robots and Systems, 2006 IEEE/RSJ International Conference on, IEEE, 2006, pp. $5177-5182$.

[22] V. Reinbold, E. Vinot, L. Garbuio, L. Gerbaud, Optimal sizing of an electrical machine using a magnetic circuit model: application to a hybrid electrical vehicle, IET Electrical Systems in Transportation 6 (1) (2016) 27-33.

[23] W. Gao, C. Mi, Hybrid vehicle design using global optimisation algorithms, International Journal of Electric and Hybrid Vehicles 1 (1) (2007) $57-70$.

[24] E. Vinot, V. Reinbold, R. Trigui, Global optimized design of an electric variable transmission for hevs., Vehicular Technology, IEEE Transactions on 65 (8) (2015) 6794-6798. doi:10.1109/TVT.2015.2479717.

[25] O. Sundstrom, D. Ambuhl, L. Guzzella, On implementation of dynamic programming for optimal control problems with final state constraints, Oil \& Gas Science and Technology-Revue de l'Institut Français du Pétrole 65 (1) (2010) 91-102. 